\title{
RESEARCH
}

Open Access

\section{Synergistic modulation of signaling pathways to expand and maintain the bipotency of human hepatoblasts}

Tingcai Pan 1,2,3,4 , Yan Chen 1,3,4 , Yuanqi Zhuang ${ }^{1,3,4}$, Fan Yang ${ }^{1,3,4}$, Yingying $X^{13}{ }^{1,3,4}$, Jiawang Tao ${ }^{1,2,3,4}$, Kai You ${ }^{1,3,4}$,

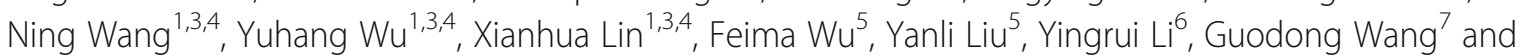
Yin-xiong $\mathrm{Li}^{1,2,3,4,8^{*}}$

\begin{abstract}
Background: The limited proliferative ability of hepatocytes is a major limitation to meet their demand for cellbased therapy, bio-artificial liver device, and drug tests. One strategy is to amplify cells at the hepatoblast (HB) stage. However, expansion of HBs with their bipotency preserved is challenging. Most HB expansion methods hardly maintain the bipotency and also lack functional confirmation.
\end{abstract}

Methods: On the basis of analyzing and manipulating related signaling pathways during HB (derived from human induced pluripotent stem cells, iPSCs) differentiation and proliferation, we established a specific chemically defined cocktails to synergistically regulate the related signaling pathways that optimize the balance of HB proliferation ability and stemness maintenance, to expand the HBs and investigate their capacity for injured liver repopulation in immune-deficient mice.

Results: We found that the proliferative ability progressively declines during HB differentiation process. Small molecule activation of Wnt or inhibition of TGF- $\beta$ pathways promoted HB proliferation but diminished their bipotency, whereas activation of hedgehog $(\mathrm{HH})$ signaling stimulated proliferation and sustained HB phenotypes. A cocktail synergistically regulating the BMP/WNT/TGF- $\beta / H H$ pathways created a fine balance for expansion and maintenance of the bipotency of HBs. After purification, colony formation, and expansion for 20 passages, HBs retained their RNA profile integrity, normal karyotype, and ability to differentiate into mature hepatocytes and cholangiocytes. Moreover, upon transplantation into liver injured mice, the expanded HBs could engraft and differentiate into mature human hepatocytes and repopulate liver tissue with restoring hepatocyte mass.

Conclusion: Our data contribute to the understanding of some signaling pathways for human HB proliferation in vitro. Simultaneous BMP/HGF induction, activation of Wnt and HH, and inhibition of TGF- $\beta$ pathways created a reliable method for long-term stable large-scale expansion of HBs to obtain mature hepatocytes that may have substantial clinical applications.

Keywords: Human iPSCs, Hepatoblasts, Expansion, Bipotency maintenance, Self-renewal

\footnotetext{
* Correspondence: li_yinxiong_iph@gibh.ac.cn

${ }^{\dagger}$ Tingcai Pan and Yan Chen contributed equally to this study as co-first authors.

${ }^{1}$ Institute of Public Health, Guangzhou Institutes of Biomedicine and Health $(\mathrm{GIBH})$, Chinese Academy of Sciences, Guangzhou 510530, China

${ }^{2}$ University of Chinese Academy of Science, Beijing 100049, China

Full list of author information is available at the end of the article
}

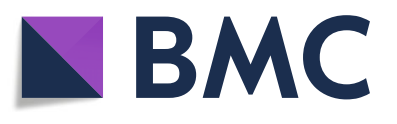

(c) The Author(s). 2019 Open Access This article is distributed under the terms of the Creative Commons Attribution 4.0 International License (http://creativecommons.org/licenses/by/4.0/), which permits unrestricted use, distribution, and reproduction in any medium, provided you give appropriate credit to the original author(s) and the source, provide a link to the Creative Commons license, and indicate if changes were made. The Creative Commons Public Domain Dedication waiver (http://creativecommons.org/publicdomain/zero/1.0/) applies to the data made available in this article, unless otherwise stated. 


\section{Background}

Hepatocyte transplantation and bio-artificial liver support have been clinically evaluated as effective methods for compensation of lost liver function and an alternative to liver transplantation [1-4]. However, these two methods are hindered by the shortage of viable organ donation and dysfunction of hepatocyte in vitro culture [5]. Thus, an alternative strategy to meet the demand for functional hepatocyte supply would represent a major clinical advance. Human pluripotent stem cell (hPSC)derived hepatic lineage is considered to be a potentially good cell source for cell-based therapies and drug development process $[6,7]$. The use of human embryonic stem cells (ESCs) in clinical trials is limited due to their low availability and ethical concerns regarding their use. However, ethical issues and intensive immunosuppressive treatment can be avoided by using patient-specific iPSCs [8]. Therefore, iPSC-derived hepatic cells are an ideal source for autologous cell-based therapy and extracorporeal artificial liver application.

Differentiation of hPSCs into hepatic cells has been achieved and improved during the last several years [9-11]. However, there are several limitations, which have not yet been addressed, especially related to their application in clinical trials and drug toxicology tests. The limitations include (a) heterogeneity of resulting cultures, as well as unpurified target cells; (b) low or ineffective hepatocyte-like functionality; (c) difficulty in obtaining large-scale hepatic cell populations. It is anticipated that therapeutic application would require $10^{9}$ graded hepatic cells per treatment $[12,13]$, while bio-artificial liver device application and drug discovery need even more. Thus, there is an urgent need to establish methods that can produce functional hepatic cells of high quality in large quantities.

In vitro culture of hepatocytes has low proliferative potential, while hepatoblasts (HBs) are capable of selfrenewal and with potency to differentiate into hepatocytes and cholangiocytes. An ideal strategy would be to enable directed differentiation of human iPSCs to HBs with simultaneous cell expansion, which would enable up-scaling hepatic cell production. The expansion of HBs derived from hPSCs has been previously reported [14-18]. However, these studies relied mainly only on biomarker analyses to evaluate the bipotency and lacked many of the functional analyses and confirmation through animal transplantation was limited. In addition, some of them included undefined components such as fetal bovine serum or feeder cells leading to safety concerns for clinical applications [15, 17-19].

Recent studies identified small molecules which are used in the expansion of human HBs in defined chemical conditions $[17,20,21]$. However, these proliferative HBs were refractory to mature hepatocyte induction, which results in low ALB-positive cells and poor metabolic activity [14].
One possible explanation for the inability to derive functional hepatocytes is unstable maintenance of HB phenotype during expansion, which may be due to an ambiguous mechanism. Thus, a detailed understanding of the proliferation and differentiation mechanisms of human $\mathrm{HB}$ is important to establish a defined chemical method for expansion of human HB.

Here, we investigated the relationship of related signaling pathways with proliferation of human iPSC-derived HBs and established a chemically defined cocktail to synergistically regulate the related signaling pathways that optimized the balance of $\mathrm{HB}$ proliferation ability and stemness maintenance. The purified and expanded HBs stably retain phenotypes including the gene expression profile integrity and bipotency to differentiate into functional hepatocytes and cholangiocytes in vitro and in animal model. Therefore, our approach provides a defined chemical and serum-free method for long-term stable expansion of human iPSC-derived HBs for clinical applications.

\section{Methods \\ Human iPSC culture and HB differentiation}

Human iPSC lines (UC01 and UC15) and ESC line (H1) cultured in chemically defined mTeSR1 medium (Stem Cell Technologies) on a Matrigel matrix (Growth Factor Reduced, BD Bioscience). The human iPSC colonies were passaged using Accutase (life).

For the $\mathrm{HB}$ differentiation, we started the definitive endoderm (DE) stage induction first. Briefly, when human iPSCs reached nearly $70 \%$ confluence, mTeSR 1 medium was replaced with differentiation medium (RPMI1640 [Gibco], supply with $1 \times$ B27[minus insulin, Invitrogen]), containing $100 \mathrm{ng} / \mathrm{mL}$ Activin A (R\&D Systems) and $3 \mu \mathrm{M}$ CHIR99021 (CHIR) for 1 day, and on the following 2 days, CHIR was omitted from the medium. Then, DE population was cultured in differentiation medium, containing $20 \mathrm{ng} / \mathrm{mL}$ BMP2, $20 \mathrm{ng} / \mathrm{mL}$ BMP4, and $30 \mathrm{ng} / \mathrm{mL}$ FGF4 for 4 days to specify hepatic endoderm (HE), and then subsequently differentiated into HBs by treatment with differentiation medium containing $20 \mathrm{ng} / \mathrm{mL}$ BMP4 and $20 \mathrm{ng} / \mathrm{mL}$ HGF for 3 days. The medium was changed daily during the differentiation period. All grow factors were purchased from PeproTech except that indicate.

\section{HB proliferative culture}

The differentiated day 10 cells were cultured on plates that pre-coated with Matrigel, and maintained in expansion basal medium (RPMI1640, $1 \times$ B27 supplement, $1 \times$ ITS [insulin-transferrin-sodium selenite, Sigma-Aldrich]) supplemented with growth factor and small molecule combination as indicated in Fig. 3a. Growth factors and small molecules were tested at appropriate concentrations 
as routinely used, including $20 \mathrm{ng} / \mathrm{mL}$ EGF, $20 \mathrm{ng} / \mathrm{mL}$ BMP4, $20 \mathrm{ng} / \mathrm{mL}$ HGF, $20 \mathrm{ng} / \mathrm{mL}$ FGF7, $3 \mu \mathrm{M}$ CHIR, $5 \mu \mathrm{M}$ A8301, $0.5 \mu \mathrm{M}$ SAG, $10 \mu \mathrm{M}$ Forskolin (FSK, Stemgent), $10 \mu \mathrm{M}$ SB431542 (SB, Tocris), $0.5 \mu \mathrm{M}$ Dorsomorphin (DM), and $0.5 \mu \mathrm{M}$ Vismodegib (VM). Used small molecules were purchased from Selleck except indicated.

The $\mathrm{EpCAM}^{+} / \mathrm{C}-\mathrm{kit}^{-}$populations were sorted by cell flow cytometry, and single cell was seeded on Matrigel pre-coated 96-well plates and maintained in optimal $\mathrm{AB}_{10} \mathrm{CEHS}$ culture condition (expansion basal medium supplement with $5 \mu \mathrm{M}$ A8301, $10 \mathrm{ng} / \mathrm{mL}$ BMP4, $3 \mu \mathrm{M}$ CHIR, 20 ng/mL EGF, 20 ng/mL HGF, $0.5 \mu$ M SAG), for colony formation and other in vitro assays.

\section{Hepatocyte differentiation and bile duct induction}

For hepatocyte differentiation, HBs were cultured in maturation medium hepatoZYME-SFM (Gibco), supplemented with 1X GlutaMAX, $10 \mathrm{ng} / \mathrm{mL}$ OncostatinM (OSM), $0.1 \mu \mathrm{M}$ dexamethasone (DEX; Sigma-Aldrich), and $0.5 \mathrm{mM} \mathrm{NH} \mathrm{NH}_{4} \mathrm{Cl}$ (Sigma-Aldrich) for 7 days. The medium was changed daily during the differentiation period.

For cholangiocyte differentiation in monolayer, HBs were cultured in basal medium (RPMI1640 [Gibco], supply with $1 \times$ B27 [Invitrogen]), supplemented with $20 \mathrm{ng} /$ $\mathrm{mL}$ EGF and $20 \mathrm{ng} / \mathrm{mL}$ HGF for 7 days. The medium was changed daily during the differentiation period.

For 3D bile duct induction, dissociated HBs were suspended in basal medium (RPMI1640 [Gibco], supply with $1 \times$ B27 [Invitrogen]) supplemented with $20 \mathrm{ng} / \mathrm{mL}$ EGF and $20 \mathrm{ng} / \mathrm{mL}$ HGF, and mixed 1:1 with Matrigel. Then, the mixture was plated into 24 -well plates $(0.5$ $\mathrm{mL} /$ well) and placed in an incubator at $37^{\circ} \mathrm{C}$ for $2 \mathrm{~h}$ to allow the formation of 3D Matrix. The cells were cultured for approximately 1 week to allow the formation of bile duct-like structures. The medium was changed carefully every other day.

\section{Functional analyses of differentiated hepatocyte in vitro}

For the albumin secretion assay, the culture media of 24 $\mathrm{h}$ incubated in differentiated cells were collected and evaluated using the human albumin ELISA Quantitation kit (Bethyl Laboratories) according to the manufacturer's protocol. The results are representative of at least three independent experiments.

For the urea secretion assay, the culture media of $24 \mathrm{~h}$ incubated in differentiated cells were collected and stored at $-80^{\circ} \mathrm{C}$. Urea concentration was analyzed by LC/MS/MS API3000 and normalized with total cell protein concentration.

To evaluate the CYP450 activity, cultures were incubated with conventional probe substrates (CYP3A4: $6 \mu \mathrm{M}$ midazolam, CYP2C9: $10 \mu \mathrm{M}$ diclofenan, CYP2D6: $10 \mu \mathrm{M}$ dextromethorphan) respectively, for quantifying metabolite production. After 2-h exposure, the culture medium was collected and stored at $-80^{\circ} \mathrm{C}$ subsequently, and CYP450 activity was analyzed by LC/MS/ MS API3000. Metabolite products were normalized to total cell protein.

To evaluate the glycogen production and storage ability, Periodic acid-Schiff (PAS) staining was performed. The cultured cells were fixed with $4 \%$ PFA for $30 \mathrm{~min}$, and intracellular glycogen was stained using a PAS staining solution (Muto Pure Chemicals), according to the manufacturer's instructions.

\section{Animal model and hepatic cell transplantation}

Immune-deficient NOD-SCID-IL2RG ${ }^{-1-}$ mice (NSI mice, GIBH) were used as recipients of human hepatic cells. Before hepatic cell transplantation, 8-week-old NSI mice received DMN intraperitoneal injections $(7 \mathrm{mg} / \mathrm{kg}$, Sigma, $1.0 \%$ dissolved in saline) for 2 consecutive days for inducing acute liver injury. Two days later, $1 \times 10^{6}$ hepatic cells were intrasplenic transplanted into the DMN-treated NSI mice. To monitor the transplantation state, recipient mouse blood and livers were harvested at different time points after hepatic cell transplantation. Additionally, human hepatocytes that were producing the ALB protein were identified in mouse liver by an antibody specifically recognizing human ALB. Serum and plasma were separated from mouse blood and stored at $-80^{\circ} \mathrm{C}$ for liver function tests. All animal experiments were approved by the Animal Welfare Committee of GIBH. All protocols were approved by the relevant institutional animal care and use committee (IACUC).

\section{Statistical analysis}

The data were analyzed with Sigma Plot 10.0 Statistical differences between two groups were tested with a twotailed Student's $t$ test. Data is represented as mean \pm SEM. Survival data were analyzed with the Kaplan-Meier test. For all tests, ${ }^{*} p<0.05$ was considered significant.

More experimental details are described in Additional file 1. Information about the antibodies and primers used is in Additional file 1: Tables S1 and S2.

\section{Results}

Proliferative ability declined progressively during hepatic differentiation process

We adopted a stepwise differentiation protocol using serum-free chemically defined medium to induce HBs from human iPSCs based on previous protocols and reports on signaling regulation during embryonic hepatogenesis [11, 22]. Briefly, the protocol used Activin A and CHIR to induce definitive endoderm (DE) for 3 days, followed by BMP2, BMP4, and FGF4 to specify hepatic endoderm (HE) from day 4 to day 7 . The HE cells were 
further differentiated to HBs by induction of BMP4 and HGF (B4H) from day 8 to day 10. Details are described in the experimental procedures.

During the stepwise differentiation of HBs, sequential morphological changes and stage-specific protein analyses were performed at the end of each stage. At the DE stage (day 3), most cells (over 95\%) were double-positive for DE-specific transcriptional factors, FOXA2 and SOX17. At day 10, nearly homogenous stages of the differentiated cells were observed and they co-expressed factors characteristic of HBs, AFP, and HNF4 $\alpha$ (Fig. 1a, b), suggesting an effective sequential induction of iPSCs into DE and HBs. Importantly, we found that the proliferative abilities of these cells progressively declined during the differentiation process. Flow cytometry analyses showed that more Ki67 (a proliferative marker)-positive cells $(74.1 \%$ at day 3 and $60.3 \%$ at day 6$)$ were observed at early stages. These Ki67-positive cells decreased in the HB stage (12\% at day 10$)$, which was consistent with the subdued cell growth during the differentiation process (Fig. 1c). On the other hand, the expression of Ki67 gradually declined before HE stage and dropped quickly thereafter, while hepatic genes AFP and $H N F 4 \alpha$ gradually upregulated as expected during hepatic differentiation. This confirmed the poor proliferative capacity of HBs that were cultured in the differentiation medium (Fig. 1d).

This observation suggests that (a) the combination of BMP/FGF/HGF typically used for HB induction was not enough to maintain the proliferative ability and (b) multiple endogenous signaling pathways synergistically coordinate the differentiation, proliferation, and stemness
A

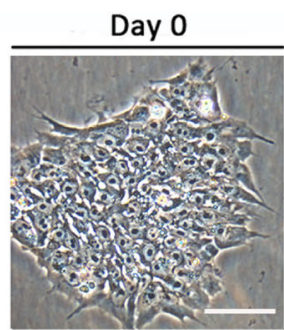

B

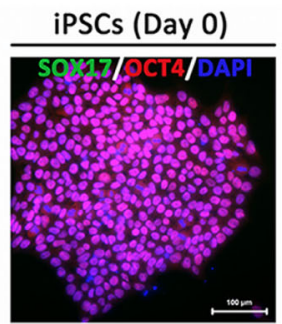

C

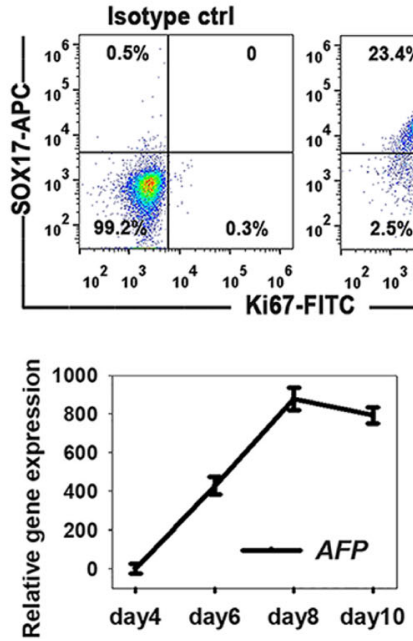

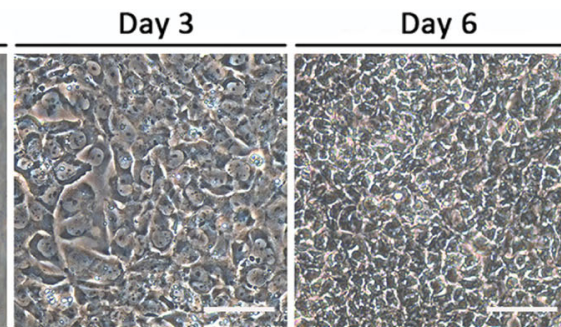

DE (Day 3)
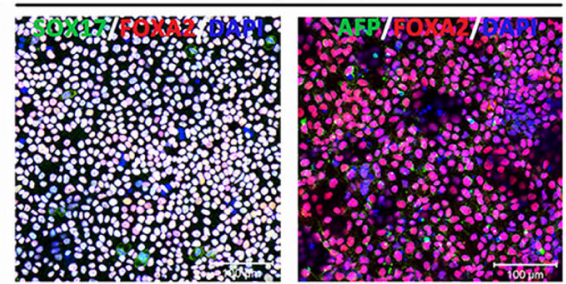

Day3
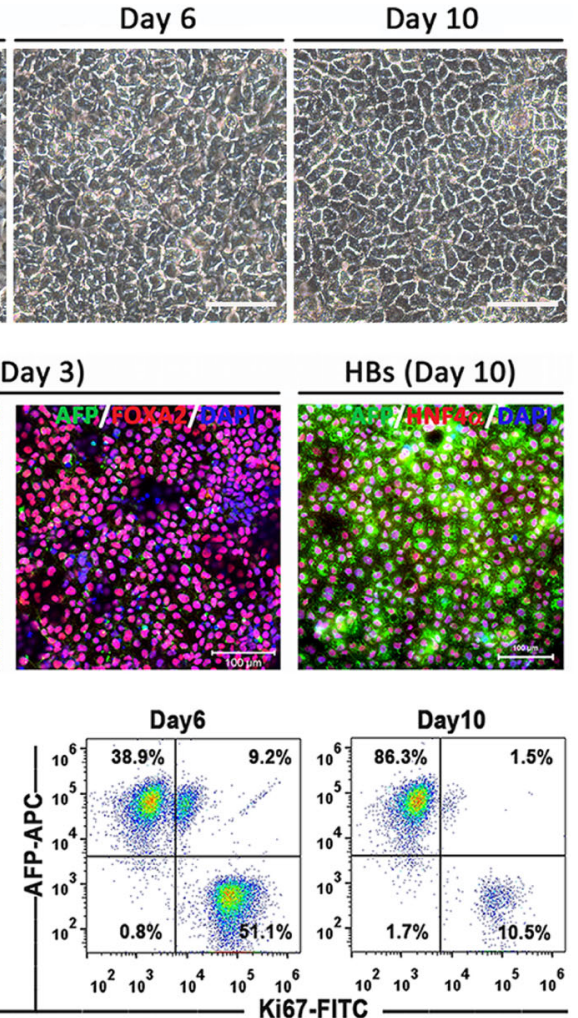

HBs (Day 10)
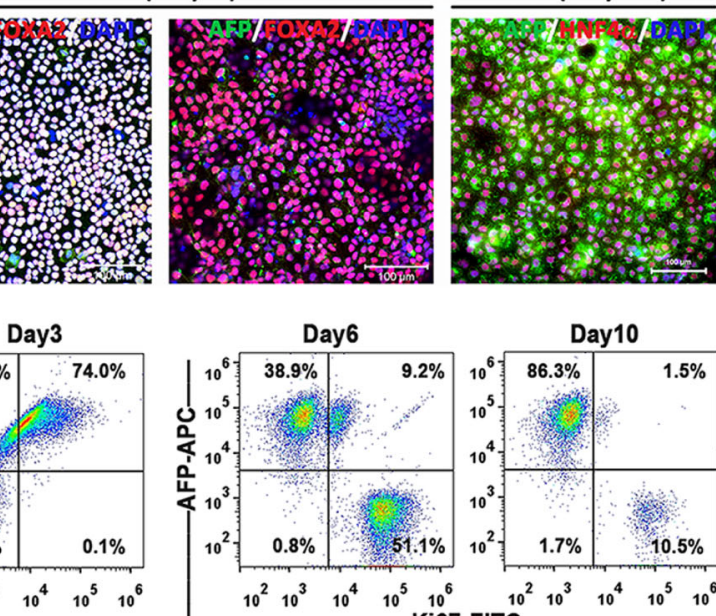
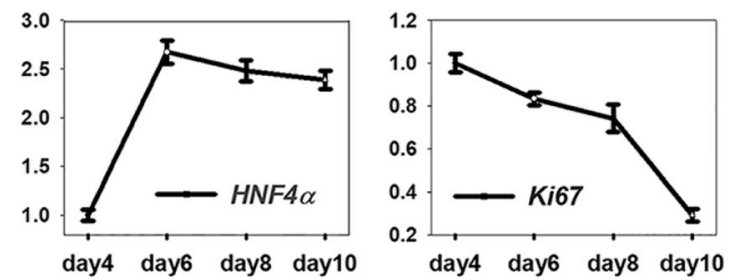

Fig. 1 Proliferative ability declined progressively during HB differentiation process. a Sequential morphological changes in the differentiation of human iPSCs into HBs. Scale bars $100 \mu \mathrm{m}$. b Stage-specific protein expression during HB differentiation process. c Flow cytometric analysis for Ki67-positive cells during HB differentiation process. d AFP, HNF4a, and Ki67 expression are analyzed by RT-PCR. Data are presented as mean \pm SEM, $n=3$ 
of $\mathrm{HB}$. Clarifying the role of these signaling mechanisms may aid in intensive proliferation of HBs and maintain their bipotency.

\section{Signaling mechanisms synergistically regulate hepatic specification and proliferation}

In order to illustrate the status of signaling pathways involved in hepatic differentiation and cell proliferation, gene expression of members of Wnt, TGF- $\beta$, and hedgehog $(\mathrm{HH})$ pathway were dynamically traced during the DE differentiation to HB stage. The expression of Wnt3 and its downstream genes Axin2 and $c-M y c$ declined sharply, indicating that Wnt signaling was downregulated. For the expression of the three TGF- $\beta$ ligand genes (Tgf- $\beta 1, T g f-\beta 2$, and $T g f-\beta 3$ ), all three of them were increased from day 4 to day 6 . From day 6 to day 10 , expecting the expression of $T g f-\beta 1$ was decreased, however, the expressions of Tgf- $\beta 2$ and Tgf- $\beta 3$ were still maintained at certain levels that may cause cell proliferation inhibition. The expression of $\mathrm{HH}$ signaling pathway genes $\mathrm{IHH}$ and $\mathrm{PATCH}$ dramatically decreased from day 6 to day 10, indicating that $\mathrm{HH}$ signaling declined from the HE to the HB stage (Fig. 2a). Meanwhile, $S H H$ showed a slight increase from day 6 to day 10, probably due to BMP2 was removed in day 8 resulting in a decreased BMP signaling, which is an antagonist for $\mathrm{SHH}$ through Smads1/5/8 [23, 24]. This change may lead to the contrast changes between $\mathrm{SHH}$ and $\mathrm{IHH}$ through $\mathrm{HH}$ non-canonical pathway.

Recent studies have demonstrated that Wnt/ $\beta$-catenin pathway support self-renewal of $\mathrm{HBs}$ and $\mathrm{HH}$ signaling is involved with hepatic progenitor cell proliferation [25, 26], whereas TGF- $\beta$ signaling induces cell growth arrest. Thus, to test whether promoting Wnt and $\mathrm{HH}$ signaling or inhibition of TGF- $\beta$ signaling improves the proliferative ability of HBs, therefore, agonist or antagonist small molecules were administrated for targeting these signaling pathways. Since Ki67 (proliferative maker) expression reached to the lowest level, therefore, we used the cells in day 10 for the proliferation measurement for following 3 days. Cells were re-plated at the same density and cultured for an additional 3 days with the basic $\mathrm{B} 4 \mathrm{H}$ medium with different agonist or antagonist administration respectively. Treatment with CHIR99021, a GSK-3 $\beta$ inhibitor that acts as a Wnt agonist, or TGF- $\beta$ signaling inhibitor A8301 or HH signaling Smoothened activator SAG enhanced Ki67 expression with $70.5 \%, 43.2 \%$, and $45.6 \%$ respectively (Fig. 2b, c). However, co-staining with AFP indicated Ki67-positive cells had a weak or negative AFP expression in the CHIR group. While in the A8301 and SAG groups, most Ki67-positive cells maintained the AFP expression levels (Fig. 2c). Further, cell growth analyses confirmed that GSK-3 $\beta$ inhibitor (CHIR99021 or CHIR98014) or TGF- $\beta$ signaling inhibitor (A8301 or
SB431542) significantly improved cell growth. Treatment with SAG also increased the proliferation of HBs, but the proliferation was less than that achieved by CHIR treatment. Interestingly, TGF- $\beta 1$ treatment also improved the proliferation slightly. In contrast, inhibition of BMP signaling by Dorsomorphin (DM) or HH signaling by Vismodegib (VM) fully blocks HB proliferation (Fig. 2d). These results demonstrated that GSK-3 $\beta$ inhibitors significantly promoted $\mathrm{HB}$ proliferation but diminished the $\mathrm{HB}$ phenotype, while TGF- $\beta$ signaling inhibition and $\mathrm{HH}$ signaling activation stimulated $\mathrm{HB}$ proliferation and also sustained the characteristics of HBs.

To define the cell fate of these HBs after treatment with signaling inhibitors, gene expression of key biomarkers was analyzed. CHIR treatment dramatically diminished the AFP expression and increased the expression of SOX17 (DE) and CDX2 (intestinal endoderm), suggesting a phenotype shift from $\mathrm{HB}$ to intestinal endoderm. The treatment with TGF- $\beta 1$ increased $A F P$ expression slightly, but also induced the expression of SOX17 and PDX1 (pancreatic). However, A8301 could block the expression of $S O X 17$ and $P D X 1$ without a significant change in AFP expression. SAG promoted AFP expression the most among these molecules. Contrarily, VM or DM not only diminished AFP expression but also induced PDX1 expression (Fig. 2e), suggesting $\mathrm{HH}$ signaling inhibition or BMP signaling inhibition may induced a cell faith shift from hepatic to pancreatic lineage.

In summary, activation of Wnt and $\mathrm{HH}$ signaling (CHIR and SAG) and inhibition of TGF- $\beta$ signaling (A8301) promote $\mathrm{HB}$ proliferation. However, CHIR alone damages the HB characteristics due to dedifferentiation into endoderm or intestinal endoderm, while $\mathrm{BMP}$ and $\mathrm{HH}$ signaling are essential for preserving the HB phenotype (Fig. 2f). Thus, we speculated that proliferation or expansion resulted in $\mathrm{HB}$ phenotype loss, which could be avoided by synergistically regulating the $\mathrm{BMP} / \mathrm{WNT} / \mathrm{TGF}-\beta / \mathrm{HH}$ signaling.

\section{Optimization of the HB expanding culture conditions}

In order to establish an optimized condition that promotes the expansion of HBs without diminishing their hepatic characteristics, as observed in our results and reported elsewhere $[14,17,20]$, we screened for synergistically regulated signaling transductions (Fig. 3a). Cell growth curves of HBs were measured during a 9-day culture period (Fig. 3b). The basic BMP4 and HGF $\left(\mathrm{B}_{20} \mathrm{H}\right)$ cocktail had minimal proliferation activity, and the majority of cells lost their epithelial shape shifting to a fibroblastic shape (Additional file 1: Figure S1). Addition of CHIR and EGF $\left(\mathrm{B}_{20} \mathrm{CEH}\right)$ could endow $\mathrm{HBs}$ with minor proliferative activity; however, the expression 

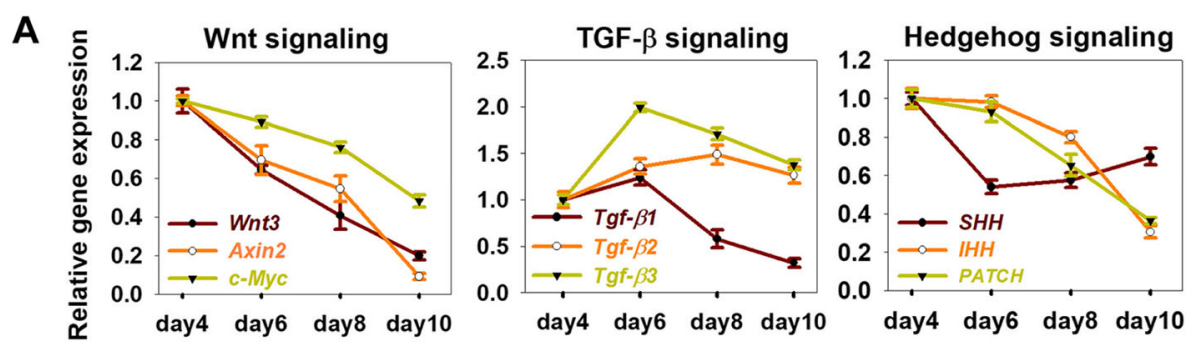

B

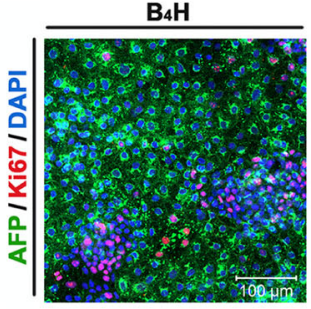

+ CHIR99021

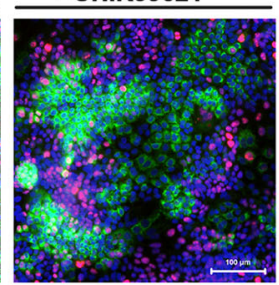

$+\mathrm{A} 8301$

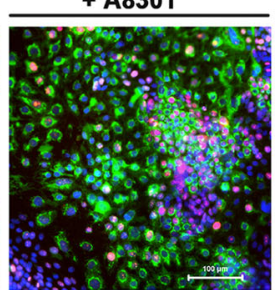

+ SAG

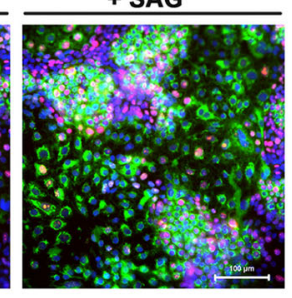

C

\begin{tabular}{|c|c|c|c|c|}
\hline Treatment & B4H & + CHIR99021 & + A8301 & + SAG \\
\hline AFP $^{+}$ & $92.3 \%+/-4.5$ & $42.5 \%+/-8.5$ & $82.5 \%+/-5.2$ & $85.3 \%+/-6.4$ \\
\hline Ki67 $^{+}$ & $15.2 \%+/-3.4$ & $70.5 \%+/-7.2$ & $43.2 \%+/-5.6$ & $45.6 \%+/-6.0$ \\
\hline AFP $^{+} / \mathrm{Ki67}^{+}$ & $8.2 \%+/-2.7$ & $10.4 \%+/-3.8$ & $30.2 \%+/-3.0$ & $35.4 \%+/-4.5$ \\
\hline
\end{tabular}

D

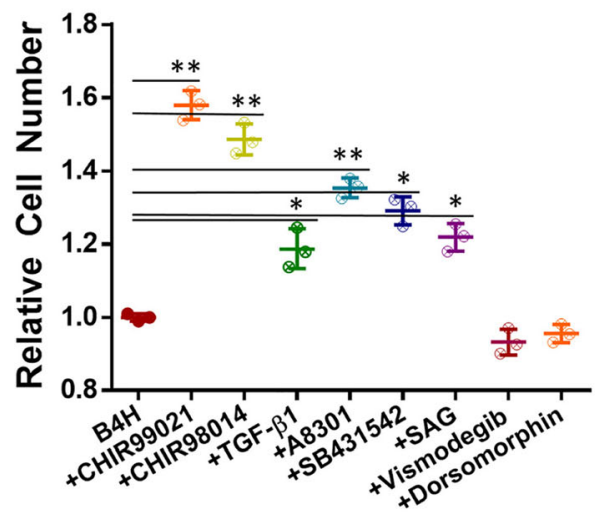

$\mathbf{F}$

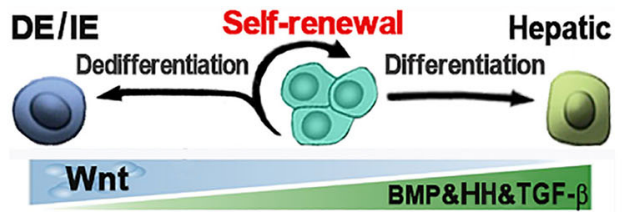

$\mathbf{E}$

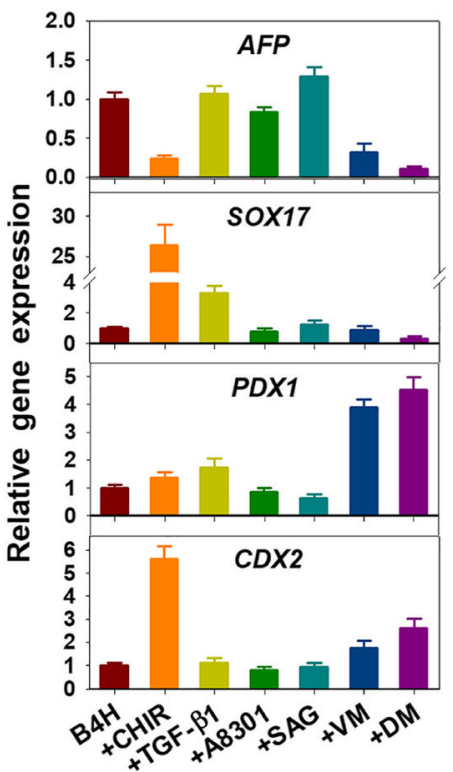

Fig. 2 Synergistic regulation of signaling pathways for hepatic specification and proliferation. a Wnt, TGF- $\beta$, and HH signaling pathway-related gene expression was analyzed by RT-PCR. Data are presented as mean $\pm \mathrm{SEM}, n=3$. $\mathbf{b}$ Immunostaining analyses of Ki67 and AFP expression after different small molecule treatment. c Efficiency of Ki67 and AFP expression after small molecule treatment, determined by counting positive cells. Efficiencies are presented as the percentage of positive cells plus or minus the SD of all fields counted. $\mathbf{d}$ Analyses of small molecule effect on HB proliferation. Data are presented as mean $\pm \mathrm{SEM}, n=3 .{ }^{*} P<0.05,{ }^{* *} P<0.01$. e Transcript markers of different cell lineages in HBs treated with different small molecules. Data are presented as mean $\pm \mathrm{SEM}, n=3$. $\mathbf{f}$ Model of signaling pathways that regulate self-renewal and differentiation of human HBs

of AFP and HNF4 $\alpha$ decreased as observed earlier (Fig. 3c, first row). Further addition of A8301 $\left(\mathrm{AB}_{20} \mathrm{CEH}\right)$ resulted in increased proliferative ability of $\mathrm{HBs}$ and improved the expression of AFP and HNF4 $\alpha$, simultaneously. BMP4 concentration of 10 $\mathrm{ng} / \mathrm{mL}$ and addition of SAG $\left(\mathrm{AB}_{10} \mathrm{CEHS}\right)$ further increased the expression of AFP and HNF4 $\alpha$ (Fig. 3c, second row). On the other hand, withdrawal of BMP4 (ACEHS and ACEH) further promoted proliferation while led to decreased AFP and HNF4 $\alpha$ expression, indicating 
A

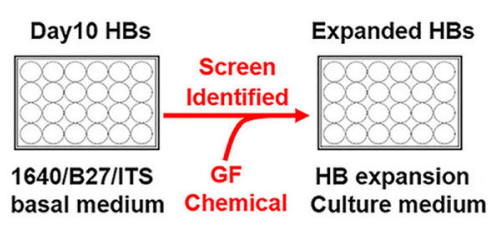

Grow Factors : HGF, BMP4, FGF7, EGF Chemicals: CHIR, A8301, SAG, FSK, SB

B

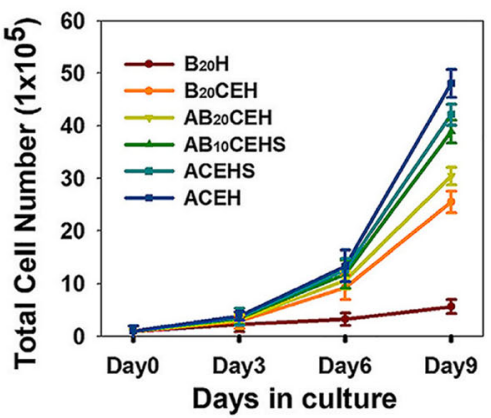

C
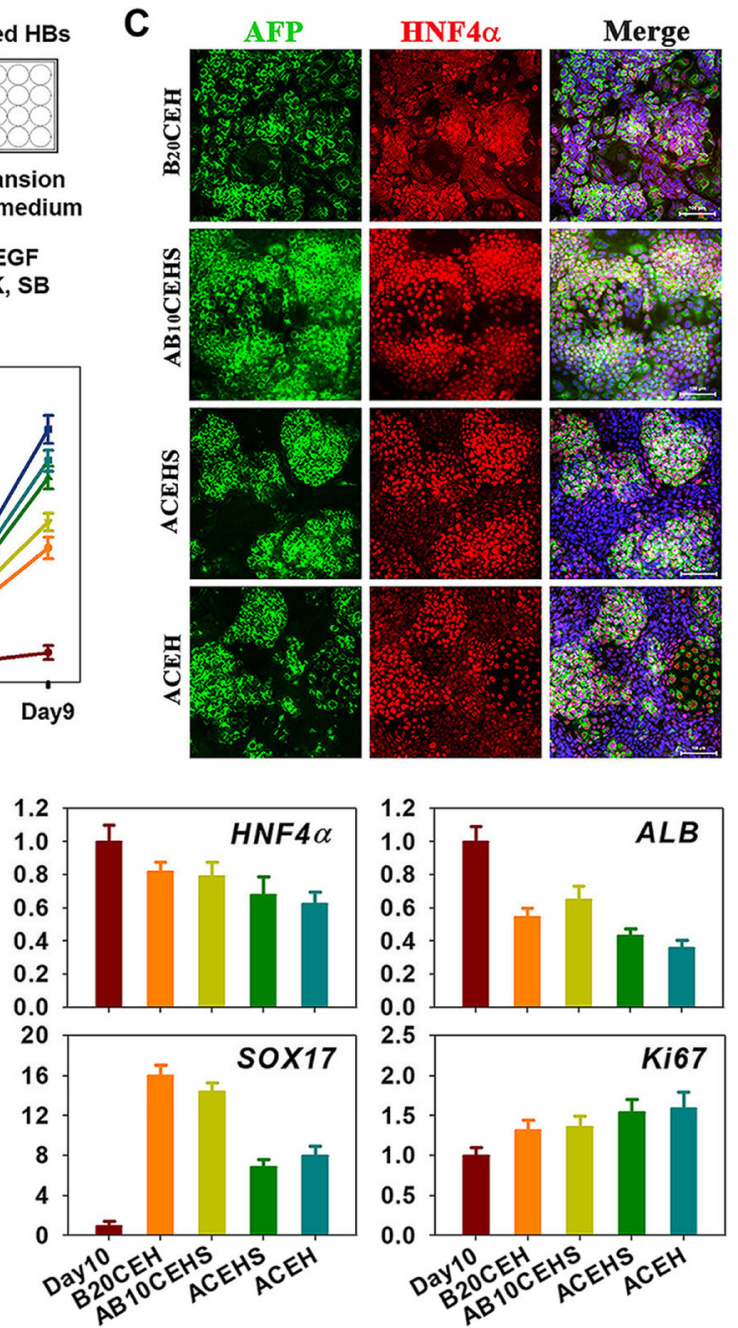

E
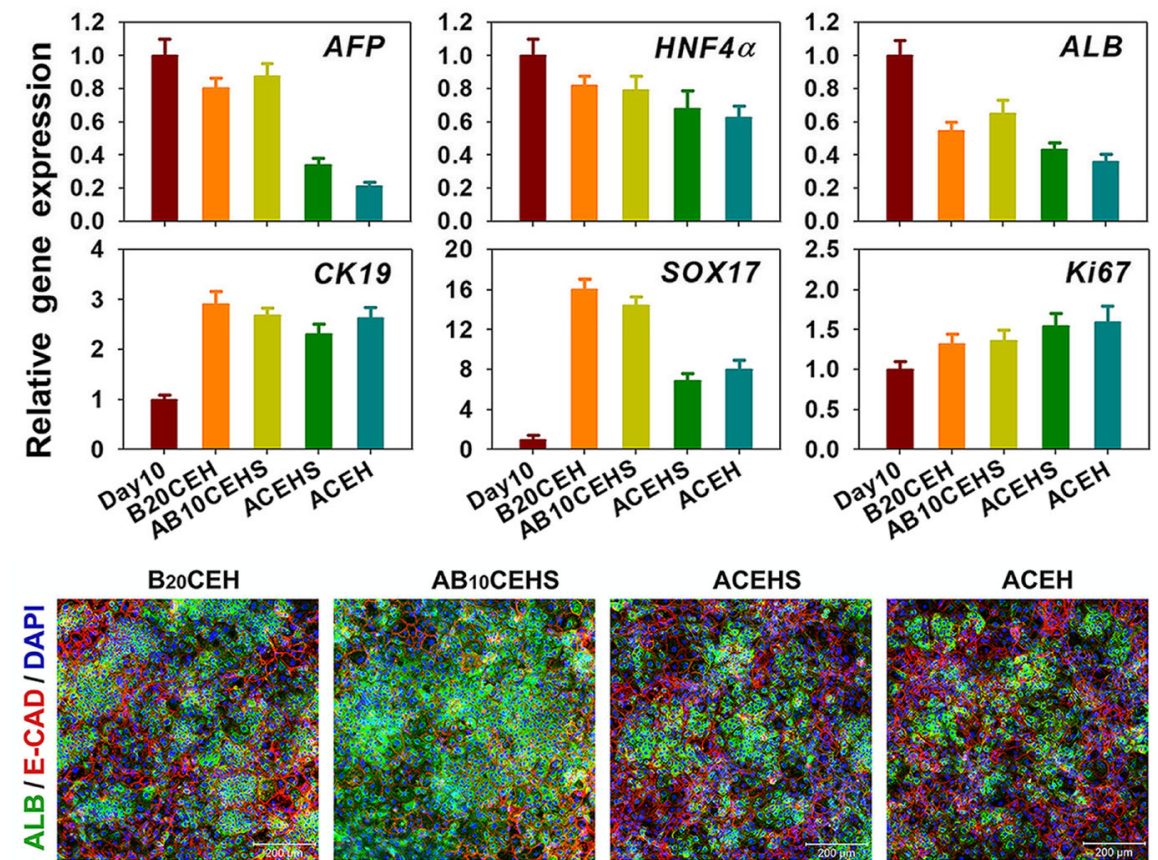

Fig. 3 Optimizing the HB expanding culture condition. a Schematic of the strategy to identify culture conditions that sustain HB expansion. $\mathbf{b}$ Growth curve of HBs cultured in different conditions. Cell growth curves were analyzed by obtaining a cell count. Data are presented as mean \pm SEM, $n=3$. A: A8301; $B_{20}: 20$ ng/mL BMP4; $B_{10}: 10$ ng/mL BMP4; C: CHIR99021; E: EGF; H: HGF; S: SAG. c AFP and HNF4a-positive cells were examined. d Quantitative RT-PCR results showing expression of hepatic genes and Ki67 in expanding HBs. Data are presented as mean \pm SEM, $n=3$. e Expressions of ALB and E-CAD were measured in the hepatocytes differentiated from HBs expanded with different conditions

the critical role of BMP signaling in HB stemness maintenance (Fig. 3c, third and fourth rows). Gene expression analyses further confirmed results that the optimal cocktail $\left(\mathrm{AB}_{10} \mathrm{CEHS}\right)$ increased the transcript level of Ki67 and maintained the expression of $\mathrm{HB}$ marker genes, including $A F P, H N F 4 \alpha$, and CK19 (Fig. 3d).

Further, hepatocyte induction was performed to analyze the differentiation capacity of HBs, which were expanded in different conditions. Immunostaining revealed that ALB and E-CAD expression was the highest in hepatocyte derived from $\mathrm{AB}_{10} \mathrm{CEHS}$ cocktail (Fig. 3e). Finally, we concluded that the optimal culture cocktail for $\mathrm{HB}$ expansion was the $\mathrm{AB}_{10} \mathrm{CEHS}$ cocktail, which increased the cell number by approximately 40 times during the 9-day culture period and maintained the hepatoblast phenotypes simultaneously. 
Purification, single-cell colony, and long-term culture for HB expansion

We next addressed whether HBs could undergo clonal expansion for long-term culture without diminishing their bipotency. We first used fluorescence-activated cell sorting (FACS) to sort EpCAM-positive and C-kitnegative iPSC-derived HBs (Fig. 4a). And colony formation assays showed that the $\mathrm{EpCAM}^{+} / \mathrm{C}$-kit ${ }^{-}$single cells were able to proliferate into colonies in $\mathrm{AB}_{10} \mathrm{CEHS}$ culture condition, and colonies were successfully expanded by serial passages (data not showed). Furthermore, the purified HBs underwent long-term culture for at least 20 passages, without significant morphologic change and obvious decrease in their proliferative ability. During expansion, these cells could be harvested, frozen, and thawed repeatedly.
A

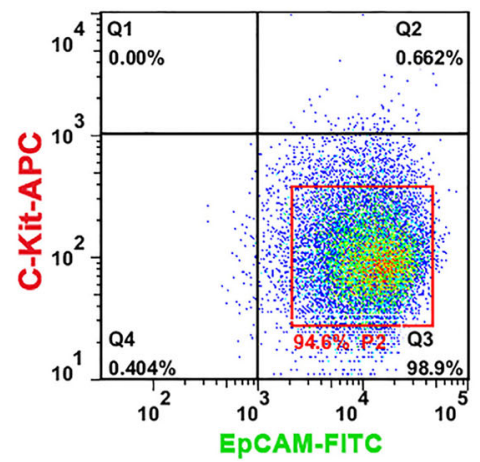

C
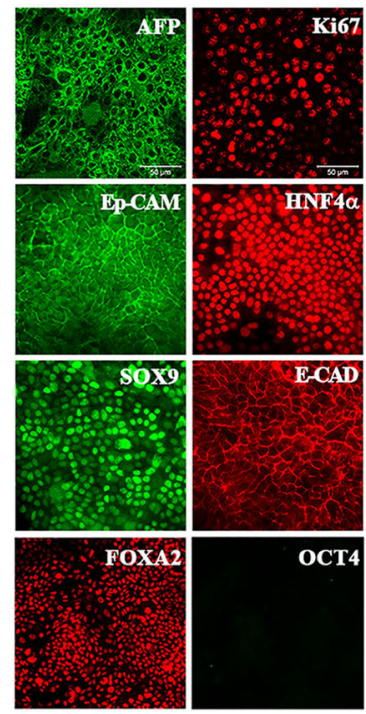

E
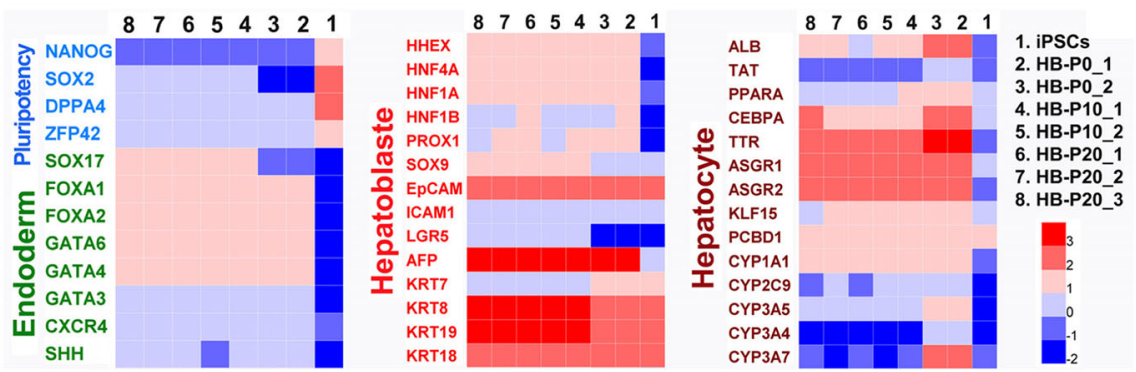

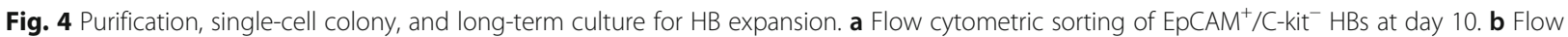
cytometric analyses of EpCAM and Ki67 expression in expanded HBs (passage 10). c Immunostaining analyses of HBs after 10 passage expansion. d Hierarchical clustering analyses of mRNA profiling of expanded HBs (HB-P10 and HB-P20), unexpanded HBs (HB-P0), and iPSCs. e Heat map comparison of the gene expression profiles endodermal, $\mathrm{HB}$, and hepatocyte among expanded and unexpanded different cell clone lines. Representative genes were indicated. Normalized fluorescent intensity values range from red (high) to blue (low) coloring 
For HB characterization, flow cytometry results showed that nearly 60\% EpCAM-positive HBs (at passage 10) co-expressed Ki67 (Fig. 4b). Immunostaining further confirmed that a considerable number of AFPpositive cells co-expressed Ki67 (Fig. 4c), indicating preferable proliferative ability of HBs. Moreover, the expanded $\mathrm{HBs}$ also expressed $\mathrm{HB}$ biomarkers like HNF4 $\alpha$, SOX9, and FOXA2, but negative for pluripotent OCT4 (Fig. 4c).

Furthermore, transcriptome comparison between early (HB-P10, HB of passage 10) and late (HB-P20, HB of passage 20) passages of the expanded HBs demonstrated a similar gene expression profile, which resembled that of unexpanded HBs (HB-P0), although some differential expression patterns were observed (Fig. 4d). The heat map and mean expression profile graphs showed that both expanded and unexpanded HBs barely expressed pluripotency genes such as NANOG and DPPA4, which were highly expressed in control iPSCs (cluster 1). Notably, the unexpanded HBs expressed mature hepatocyte transcripts, including $A L B$, APO lipoproteins $(A P O C 1, A P O C 3$, and $A P O E)$, and other proteins involved in important hepatic detoxification functions (e.g., GSTA1, GSTA2). Upon expansion, some of these gene expressions were lost (cluster 2). Furthermore, cell proliferation-related transcripts (Ki67 and LIN28A) were highly expressed in expanded HBs and iPSCs, but not in unexpanded HB samples (cluster 4). Other HB genes (CK8, CK18, and CK19) were expressed in both expanded and unexpanded HBs but not in iPSCs (cluster 5). A detailed analysis of genes related to HB bipotency, hepatic lineage, and pluripotency was performed to confirm the gene profile integrity upon expansion (Fig. 4e). Additionally, the expanded HBs also retained normal karyotypes after long-term culture (10 passages) (Additional file 1: Figure S2). Altogether, these genome-wide gene expression results indicated that both early and late passages expanded $\mathrm{HBs}$ had a similar expression profile to unexpanded HBs.

To further confirm the HB differentiation and expansion methodology, we tested two more hPSC lines (iPSC line UC15 and ESC line H1), using the optimized conditions that previously applied to the iPSC line UC01. Results showed that these two cell lines also could sequentially differentiate into DE cells and HBs, with high efficiency similarity as UC01 cells and expressed stagespecific markers (Additional file 1: Figure S3). More importantly, the $\mathrm{AB}_{10} \mathrm{CEHS}$ culture condition also could expand these HB derived from UC15 iPSCs and H1 ESCs for a long-time culture, and there were no significant differences among their proliferative abilities (Additional file 1: Figure S4A). Further immunostaining analyses showed that the majority of expanded HBs (P10) co-expressed AFP and Ki67 (Additional file 1: Figure $\mathrm{S} 4 \mathrm{~B}$ ) and other $\mathrm{HB}$ biomarkers (Additional file 1:
Figure $\mathrm{S} 4 \mathrm{C})$. It indicated this $\mathrm{AB}_{10} \mathrm{CEHS}$ expansion formula can be duplicated in other hPSC lines.

\section{Differentiation of expanded HBs into functional hepatocytes and biliary lineages in vitro}

We further investigated whether long-term culture expanded HBs retain bipotency to differentiate into both hepatocytes and biliary lineages. Firstly, cells were differentiated into hepatocyte-like cells (HLCs). The expanded HBs (HB-P10) were harvested from $\mathrm{AB}_{10} \mathrm{CEHS}$ expansion medium and then cultured in condition for hepatic maturation. After 7 days, these expanded HBs derived hepatocytes (HB-P10-Hepatocyte or HB-P10-H) displayed a homogenous and typical mature hepatocyte-like polygonal morphology, replicating the morphological features of the unexpanded HB-derived HLCs (HB-P0Hepatocyte or HB-P0-H) (Fig. 5a). Immunostaining analyses showed that there was no significant difference in yield of HLCs between the expanded and unexpanded $\mathrm{HBs}$, as evidenced by co-staining of a range of mature hepatocyte-specific proteins, including ALB, A1AT, HNF6, CK18, and CYP3A4 (Fig. 5b).

Further analyses were performed to examine typical functional activities of mature hepatocyte. HLCs showed a similar ALB secretion pattern between the expanded (HB-P10-H) and unexpanded (HB-P0-H) groups, which correspond to approximately $50 \%$ of ALB secretion of the human primary hepatocyte (PH) (Fig. 5c). Next, we assessed the detoxification functions of the HLCs by characterizing the activities of cytochrome P450 (CYP) enzymes. Three CYP isoforms were tested by measuring the increase in CYP isoform metabolites in response to exposure to their respective probe substrates. There was no statistically significant difference in all three CYP isoforms' activity between expanded and unexpanded HBderived HLCs (Fig. 5d). The measurement of urea secretion indicated that both HLC groups were similar, about one third the secretion by the PH (Fig. 5e). Periodic acid-Schiff staining (PAS) showed that both HLC groups displayed similar cytoplasmic glycogen storage ability (Fig. 5f). Undifferentiated iPSC was used as a negative control. For confirmation purposes, the expanded HB derived from two more hPSC lines (iPSC UC15 and ESC H1) were parallel tested as the UC01 for hepatocyte differentiation, and similar maturation and functional results were observed (Additional file 1: Figure S5).

Next, we investigated whether HBs can differentiate into cholangiocyte-like cells and form bile duct-like structure. After 7 days of cholangiocyte induction in monolayer culture, CK19-positive cells were observed, although ALB-positive HLCs were also observed in the culture (Additional file 1: Figure S6A, left). After approximately 1 week in 3D culture, HBs formed bile ductlike structures. These bile duct-like structures 

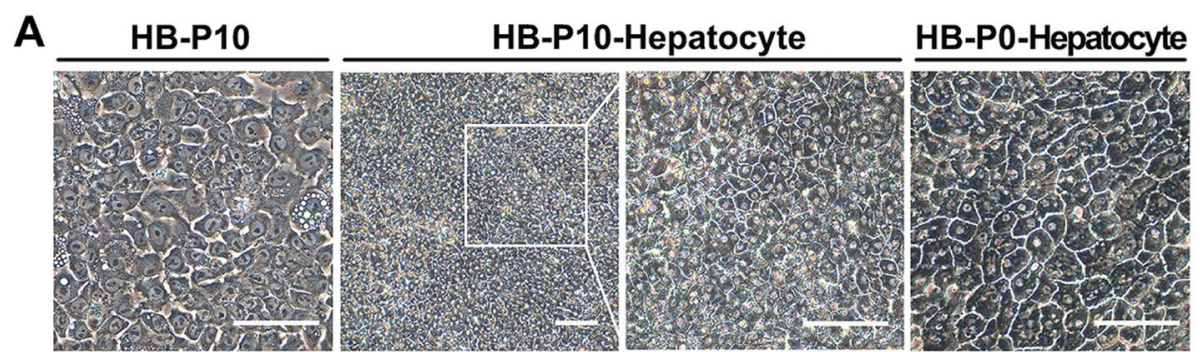

B
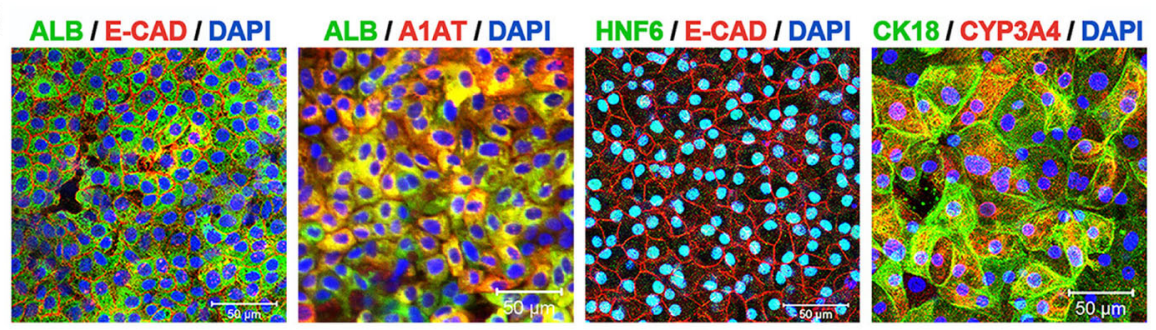

C

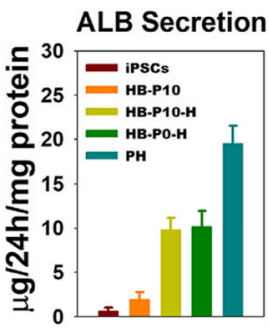

D
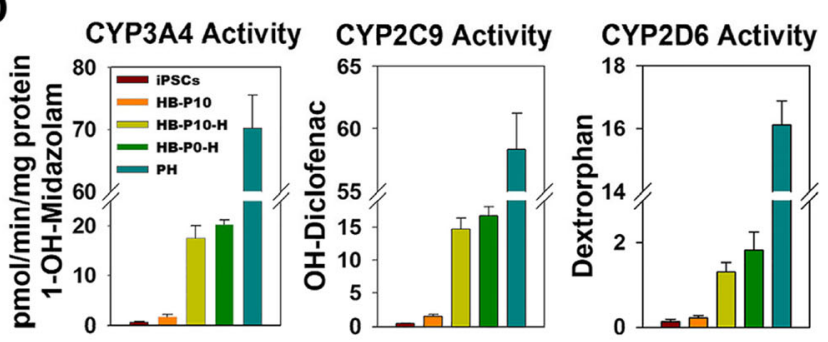

E
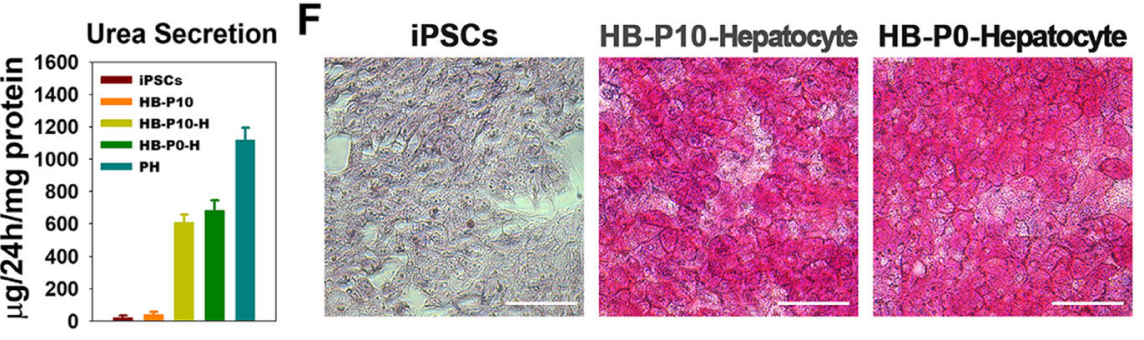

Fig. 5 Differentiation of expanded HBs into functional hepatocytes in vitro. a Phase-contrast images of differentiating cells. Scale bar $100 \mu$ m. b Expanded HB-derived HLCs (HB-P10-Hepatocyte) expressed mature hepatocyte-specific markers. c ALB secretion was analyzed. Data are presented as mean $\pm \mathrm{SEM}, n=3$. $\mathbf{d}$ CYP450 activity assay of different origin of hepatocytes. Data are presented as mean $\pm \mathrm{SEM}, n=3$. e Urea secretion among different origin of hepatocytes. Data are presented as mean $\pm \mathrm{SEM}, n=3$. $\mathbf{f}$ Periodic acid-Schiff (PAS) staining on different origin of hepatocytes. Scale bar represents $100 \mu \mathrm{m}$

demonstrated epithelial polarity with CK7 and CK19 on the basolateral region and $\mathrm{F}$-actin at the apical region (Additional file 1: Figure S6A, Right). Similar results were also obtained on two other expanded HBs derived from UC15 or H1 (Additional file 1: Figure S6B). Taken together, these results indicated that expanded HBs retained bipotency after long-term expansion, with the ability to differentiate into both hepatocytes and biliary lineages in vitro.

\section{Transplantation of expanded HBs rescued acute liver failure}

To determine whether the expanded HBs could mature into functional hepatocytes in vivo, we transplanted HBs or
HB-derived HLCs into DMN-induced acute liver failure of NSI mice (Fig. 6a). The Kaplan-Meier survival estimates were determined for 7 days after cell transplantation. In the sham control group, death caused by acute liver failure occurred as early as 3 days and nearly half (6 of 12) died within 7 days after the DMN injection. For the experimental groups ( $n=12$ per group), survival rates of all three groups (unexpanded HBs (HB-P0), expanded HBs (HBP10), or expanded HB-derived HLCs (HB-P10-Hepatocyte)) were over $85 \%$ throughout the examination period (Fig. 6b).

Hematoxylin and eosin (H\&E) staining displayed massive necrosis loci associated with inflammatory cell infiltration in the liver, which was noted 2 days after 

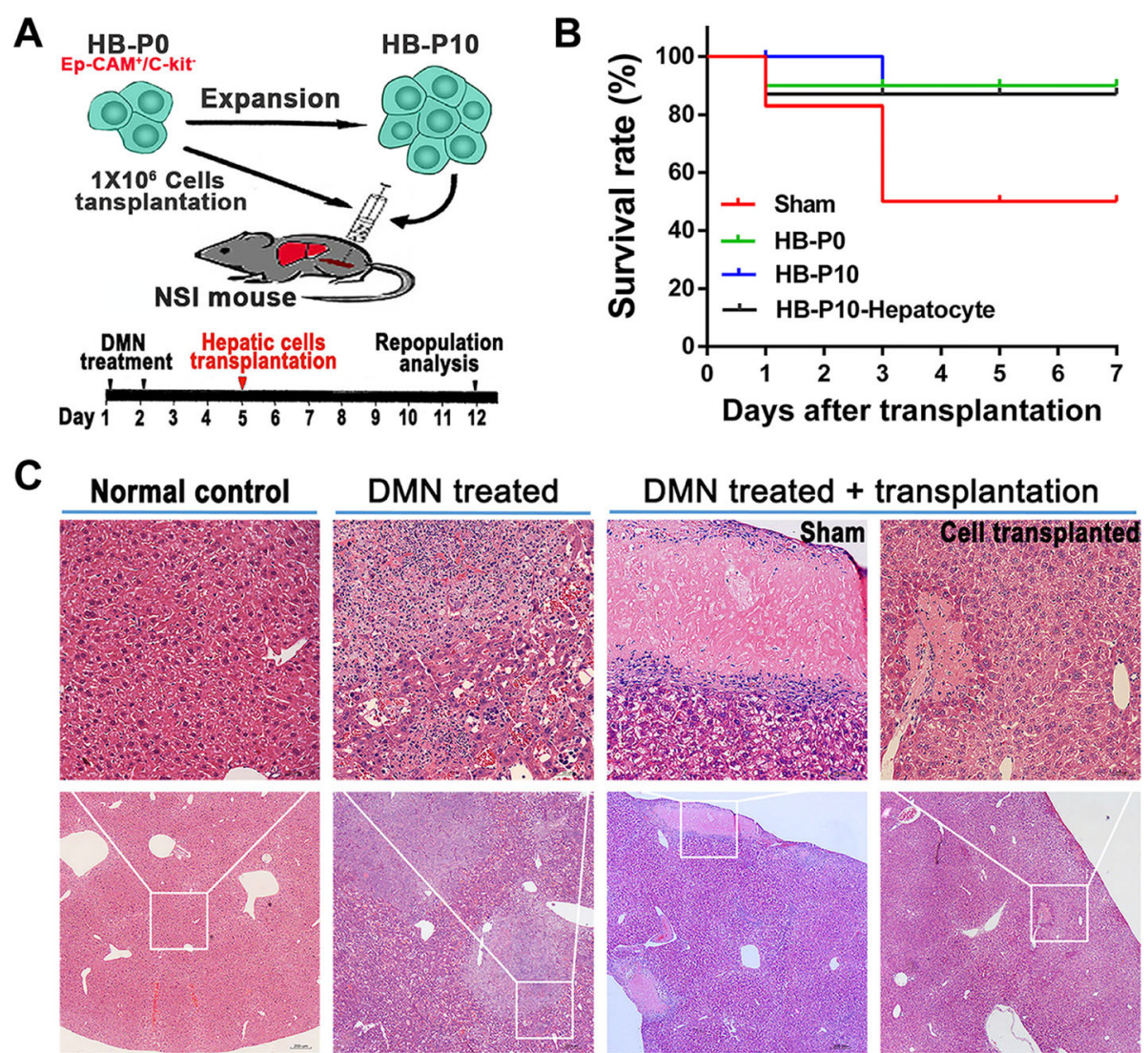

Fig. 6 Transplantation of expanded HBs rescued acute liver failure. a Schematic diagram depicting immune-deficiency mouse liver injury model and hepatic cell transplantation experimental schedule. b Survival curve of mice. c Hematoxylin and eosin staining in mouse liver

DMN-induced acute liver failure (Fig. 6c, second panel). After 1 week of hepatic cell transplantation, the necrosis loci dramatically decreased and morphologically restored the recipient liver tissues. In contrast, in the sham control liver, the necrosis loci were still widespread (Fig. 6c, right).

\section{Repopulation of mouse injured liver by transplanted HBs}

To analyze repopulation efficiency, immunostaining with human ALB antibody was conducted 1 week after transplantation. Representative patterns of positive staining of human ALB in the HBs and HB-derived hepatocytes transplanted liver were showed, indicating that both unexpanded (HB-P0) and expanded HBs (HB-P10) could differentiate into mature hepatocyte in vivo. Expanded HB-derived HLCs (HB-P10-Hepatocyte) also could engraft in the recipient liver (Fig. 7a). The overall results for experimental groups showed similar percentage of engrafted cells in recipient mouse liver sections and that human ALB was detected in 21 out of 25 mice receiving hepatic cells (Fig. 7b). Examination of human ALB in the mice's serum after hepatic cell transplantation showed similar human ALB secretion in HB-P10 and HB-P10-Hepatocyte transplanted groups (Fig. 7c). Four weeks after transplantation, human ALB-positive cells were observed both in expanded HBs and hepatocytes transplanted mouse liver (Fig. 7d), which was consistent with the human ALB secretion data.

No teratomas or other tumor types were found in any of the transplanted recipients during a 4-week time frame. Therefore, we concluded that purified and longterm expanded HBs could engraft and differentiate into hepatocytes after transplantation.

\section{Discussion}

HB proliferation is an integral process in embryogenesis, and it is observed that the cell proliferation ability gradually declines during $\mathrm{HB}$ induction in vitro. Thus, it is difficult to obtain sufficient population of HBs in direct hepatic differentiation protocols, limiting their largescale production to meet the clinical demands. Therefore, there is an urgent need to establish efficient method for generating abundant and homogeneous HBs.

In this study, we demonstrated that CHIR could improve the $\mathrm{HB}$ growth significantly, which was in line with recent reports [14, 25, 27]. However, CHIR treatment led to loss of $\mathrm{HB}$ identity and reversing the gene expression pattern from hepatic to an intestinal 


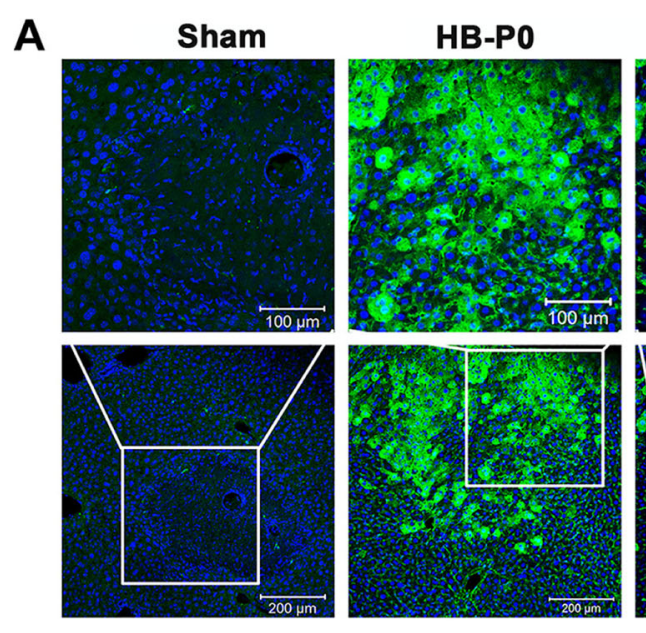

B

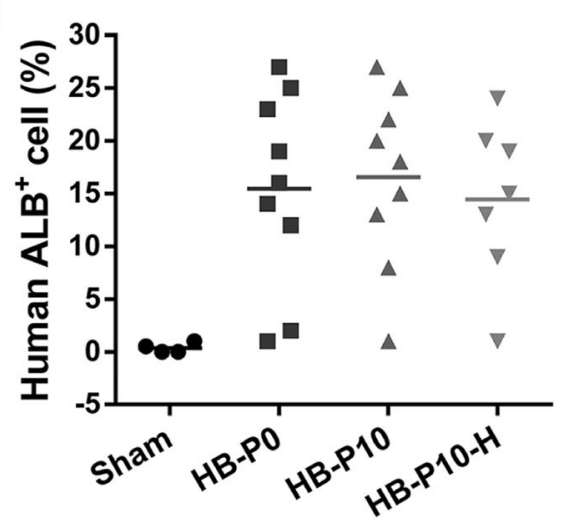

D

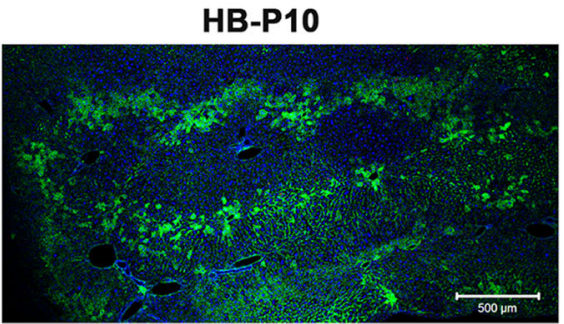

HB-P10
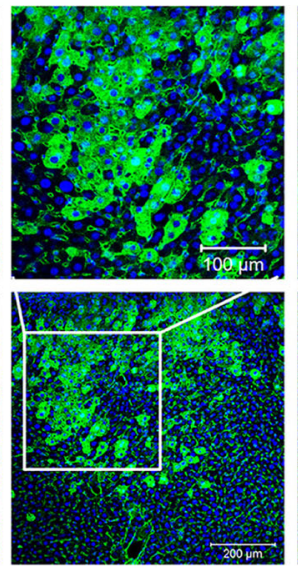

C

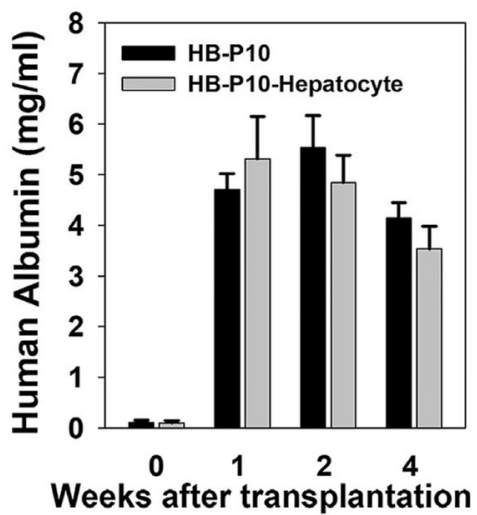

HB-P10-Hepatocyte

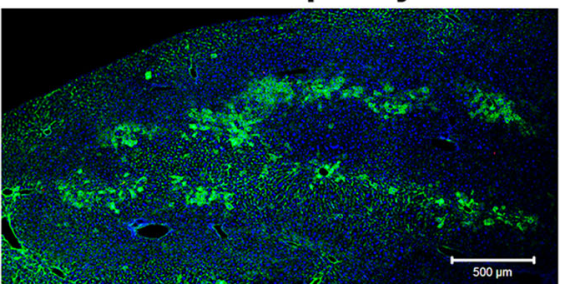

Fig. 7 Repopulation of mouse injured liver by transplanted HBs. a Engraftment of transplanted human hepatic cells (human ALB, green) in mouse liver after 1 week transplantation. b Percentages of engrafted cells in recipient mouse liver sections 1 week after transplantation. c Human ALB secretion in the mouse serum. Data are presented as mean \pm SEM, $n=4$. $\mathbf{d}$ Repopulation with transplanted cells in mouse liver 4 weeks after transplantation

endoderm pattern. This result is consistent with previous studies, which showed that Wnt/beta-catenin signaling acts directly on endoderm to induce CDX2, and direct intestinal induction $[28,29]$. Another recent study proposed that CHIR increases the transcription of hepatic genes at the HB stage, which was contrary to our results. This may be attributed to synergistic action of TGF- $\beta 1$ and HGF used in the previous study [25]. In addition, another recent study reported that inhibition of Wnt signaling using WIF-1 and DKK-1 facilitated the acquisition of hepatic lineage [9]. These findings suggest a dual role of Wnt signaling in $\mathrm{HB}$ differentiation and expansion.

We also demonstrated that simultaneous inhibition of TGF- $\beta$ and activation of $\mathrm{HH}$ signaling could improve selfrenewal, proliferation, and bipotency maintenance of HBs. This result is consistent with previous reports that inhibition of TGF- $\beta$ signaling could maintain phenotype of HBs by inhibiting cell differentiation towards cholangiocytes [30]. Other reports demonstrated that TGF- $\beta$ signaling regulate the differentiation of $\mathrm{HBs}$ towards bile ductal cells in liver development and regeneration [31, 32]. $\mathrm{HH}$ 
signaling plays an inhibitory role for the pancreas in the early developmental stage. On the other hand, it promotes the proliferation and differentiation of murine and human hepatic progenitors $[26,33,34]$. It is noteworthy that BMP signaling also plays a vital role in bipotency maintenance and proliferation of HBs. In the absence of BMP signaling, the differentiation shifts to other lineages [35].

Considering the overall profile of hepatic $(A F P)$, pancreatic (PDX1), and intestinal (CDX2) markers, we assume that expanding HBs require cross-talk between signaling pathways and sequential balance to sustain its bipotency. We treated HBs with CHIR and A8301 to stimulate its proliferation and simultaneously integrated $\mathrm{BMP} / \mathrm{HH}$ signals during expansion to block pancreatic and intestinal endoderm differentiation, which resulted in hepatic specification. After screening multiple cocktail combinations, we established that $\mathrm{AB}_{10} \mathrm{CEHS}$ cocktail could stably support the expansion of HBs by selfrenewal, without diminishing their bipotency. The expanded HBs retained the ability to differentiate into both functional hepatocytes and biliary lineages. The HBderived HLCs express CYP3A4 and other hepatocytespecific proteins. Moreover, the CYP enzyme metabolic activity of the HLCs were comparable to freshly isolated $\mathrm{PH}$, suggesting a valuable alternative cell resource of these cells in artificial liver support system and drug toxicology analyses.

So far, the repopulation capacity of transplanted hepatocyte has been limited. Previous study reported that transplanted HBs was able to repopulate the liver and improve liver function [36]. A recent study even demonstrated that fetal liver progenitor cells could replace liver mass to a greater extent than hepatocytes [37]. In addition, another recent study reported that transplanted mouse hepatic progenitor cells of biliary origin demonstrated bi-lineage differentiation into hepatocytes and cholangiocytes, causing significant structural and functional improvement of the mouse injured liver [38]. In our present study, HBs transplanted into NSI mice with acute liver failure could engraft and differentiate into hepatocytes, which restored hepatocyte mass. This led to considerable liver repopulation and successfully bridged the acute liver failure recipients through the critical period for survival.

\section{Conclusions}

In summary, our experimental setting in which small molecules mediated exogenous modulation of signaling pathways is sufficient for the expansion of HBs derived from human iPSCs. This study provides strong in vitro evidence supporting the possibility for $\mathrm{HB}$ expansion without affecting its bipotency. Although more detailed analyses and more stringent validations are required, our study provides an ideal in vitro platform for investigating the mechanism of human HB expansion. Furthermore, this chemically defined and serum-free hepatic differentiation and expansion cocktail can ensure self-renewal proliferation of human HBs that holds a great potential for $\mathrm{HB}$ transplantation mediated repair of liver injuries.

\section{Supplementary information}

Supplementary information accompanies this paper at https://doi.org/10. 1186/s13287-019-1463-y.

Additional file 1. Supporting information

\section{Abbreviations}

hPSCs: Human pluripotent stem cells; iPSCs: Induce pluripotent stem cells; ESCs: Embryonic stem cells; HBs: Hepatoblasts; HH: Hedgehog; DE: Definitive endoderm; HE: Hepatic endoderm; HLCs: Hepatocyte-like cells; PH: Primary hepatocyte; FACS: Fluorescence-activated cell sorting; NSI mice: NOD-SCIDIL2RG ${ }^{-1-}$ mice; CHIR: CHIR99021; DM: Dorsomorphin; VM: Vismodegib; SB: SB431542; FSK: Forskolin; CYP: Cytochrome P450

\section{Acknowledgements}

The authors thank the National Basic Research Program of China and Guangdong Province Science and Technology Plan for the funding support.

\section{Authors' contributions}

TP and YC contributed equally to this work. TP wrote the manuscript; YC, YZ, $F Y, Y X$ and $K Y$ revised the manuscript; TP performed the experiments and analyzed the data; $Y C$ performed the animal experiments and function assays of hepatocytes; JT, NW, FW, and YLL assisted with the experiments and analyzed the data; YRL and GW assisted with the sequencing experiments and analyzed the data; $X L$ and $Y W$ assisted with the statistical analysis; YXL directed the study, critical revised and final approval of the manuscript. All authors read and approved the final manuscript.

\section{Funding}

This work was supported by National Basic Research Program of China (973 program, 2015CB964700), The National Natural Science Foundation of China (31871379), the Chinese Government Grant (ODCCC2268), Guangdong Province Science and Technology Plan (2018A050506070, 2016B030301007, 2015B020230007, and 2014B020225004), Guangzhou City Science and Technology Plan (201704020212), Frontier Research Program of Guangzhou Regenerative Medicine and Health Guangdong Laboratory (2018GZR110105011).

\section{Availability of data and materials}

The datasets supporting the conclusions of this article are included within the article.

\section{Ethics approval and consent to participate}

All procedures were conducted with the approval of the ethics committee of $\mathrm{GIBH}$ and in accordance with the Animal Welfare \& Ethics Committee of $\mathrm{GIBH}$.

Consent for publication

Not applicable.

\section{Competing interests}

The authors declare that they have no competing interests.

\section{Author details}

${ }^{1}$ Institute of Public Health, Guangzhou Institutes of Biomedicine and Health $(\mathrm{GIBH})$, Chinese Academy of Sciences, Guangzhou 510530, China. ${ }^{2}$ University of Chinese Academy of Science, Beijing 100049, China. ${ }^{3}$ Key Laboratory of Regenerative Biology, South China Institute for Stem Cell Biology and Regenerative Medicine, Guangzhou Institutes of Biomedicine and Health, Chinese Academy of Sciences, Guangzhou 510530, China. ${ }^{4}$ Guangdong Provincial Key Laboratory of Biocomputing, Guangzhou Institutes of Biomedicine and Health, Chinese Academy of Sciences, Guangzhou 510530, 
China. ${ }^{5}$ The Second Affiliated Hospital, Guangzhou Medical College, Guangzhou 510260, China. ${ }^{6}$ iCarbonX(Shenzhen) Company Limited, Shenzhen 518000, China. ${ }^{7}$ The First Affiliated Hospital, Sun Yat-Sen University, Guangzhou 510080, China. ${ }^{8}$ Guangzhou Regenerative Medicine and Health Guangdong Laboratory, Guangzhou 510005, China.

\section{Received: 8 June 2019 Revised: 24 September 2019} Accepted: 21 October 2019 Published online: 02 December 2019

\section{References}

1. Dhawan A, Mitry RR, Hughes RD. Hepatocyte transplantation for liver-based metabolic disorders. J Inherit Metab Dis. 2006;29(2-3):431-5.

2. Khan AA, Parveen N, Mahaboob VS, Rajendraprasad A, Ravindraprakash HR, Venkateswarlu J, Rao P, Pande G, Narusu ML, Khaja MN, Pramila R, Habeeb A, Habibullah CM. Management of hyperbilirubinemia in biliary atresia by hepatic progenitor cell transplantation through hepatic artery: a case report. Transplant Proc. 2008;40(4):1153-5.

3. Khan AA, Parveen N, Mahaboob VS, Rajendraprasad A, Ravindraprakash HR, Venkateswarlu J, Rao P, Pande G, Narusu ML, Khaja MN, Pramila R, Habeeb A, Habibullah CM. Treatment of Crigler-Najjar syndrome type 1 by hepatic progenitor cell transplantation: a simple procedure for management of hyperbilirubinemia. Transplant Proc. 2008;40(4):1148-50.

4. Dhawan A, Puppi J, Hughes RD, Mitry RR. Human hepatocyte transplantation: current experience and future challenges. Nat Rev Gastroenterol Hepatol. 2010;7(5):288-98.

5. Handa K, Matsubara K, Fukumitsu K, Guzman-Lepe J, Watson A, SotoGutierrez A. Assembly of human organs from stem cells to study liver disease. Am J Pathol. 2014;184(2):348-57.

6. Hansel MC, Davila JC, Vosough M, Gramignoli R, Skvorak KJ, Dorko K, Marongiu F, Blake W, Strom SC. The use of induced pluripotent stem cells for the study and treatment of liver diseases. Curr Protoc Toxicol. 2016;67: 14-3 1-14 1327.

7. Hannoun Z, Steichen C, Dianat N, Weber A, Dubart-Kupperschmitt A. The potential of induced pluripotent stem cell derived hepatocytes. J Hepatol. 2016;65(1):182-99.

8. Raab S, Klingenstein M, Liebau S, Linta L. A comparative view on human somatic cell sources for iPSC generation. Stem Cells Int. 2014:2014:768391.

9. Pettinato G, Ramanathan R, Fisher RA, Mangino MJ, Zhang N, Wen X. Scalable differentiation of human iPSCs in a multicellular spheroid-based 3D culture into hepatocyte-like cells through direct Wnt/beta-catenin pathway inhibition. Sci Rep. 2016;6:32888.

10. Ng S, Schwartz RE, March S, Galstian A, Gural N, Shan J, Prabhu M, Mota MM, Bhatia SN. Human iPSC-derived hepatocyte-like cells support Plasmodium liver-stage infection in vitro. Stem Cell Reports. 2015:4(3):34859.

11. Kajiwara M, Aoi T, Okita K, Takahashi R, Inoue H, Takayama N, Endo H, Eto K, Toguchida J, Uemoto S, Yamanaka S. Donor-dependent variations in hepatic differentiation from human-induced pluripotent stem cells. Proc Natl Acad Sci U S A. 2012;109(31):12538-43.

12. Hansel MC, Gramignoli R, Skvorak KJ, Dorko K, Marongiu F, Blake W, Davila J, Strom SC. The history and use of human hepatocytes for the study and treatment of liver metabolic diseases. Curr Protoc Toxicol. 2014;62:14-2 123.

13. Cantz T, Sharma AD, Ott M. Concise review: cell therapies for hereditary metabolic liver diseases-concepts, clinical results, and future developments. Stem Cells. 2015;33(4):1055-62.

14. Zhang M, Sun P, Wang Y, Chen J, Lv L, Wei W, Jin C, Li W. Generation of self-renewing hepatoblasts from human embryonic stem cells by chemical approaches. Stem Cells Transl Med. 2015;4(11):1275-82.

15. Tsuruya K, Chikada H, Ida K, Anzai K, Kagawa T, Inagaki Y, Mine T, Kamiya A. A paracrine mechanism accelerating expansion of human induced pluripotent stem cell-derived hepatic progenitor-like cells. Stem Cells Dev. 2015;24(14):1691-702.

16. Kido T, Koui Y, Suzuki K, Kobayashi A, Miura Y, Chern EY, Tanaka M, Miyajima A. CPM is a useful cell surface marker to isolate expandable bi-potential liver progenitor cells derived from human iPS cells. Stem Cell Reports. 2015;5(4): 508-15

17. Fukuda T, Takayama K, Hirata M, Liu YJ, Yanagihara K, Suga M, Mizuguchi H, Furue MK. Isolation and expansion of human pluripotent stem cell-derived hepatic progenitor cells by growth factor defined serum-free culture conditions. Exp Cell Res. 2017;352(2):333-45.
18. Takayama K, Nagamoto Y, Mimura N, Tashiro K, Sakurai F, Tachibana M, Hayakawa T, Kawabata K, Mizuguchi H. Long-term self-renewal of human ES/iPS-derived hepatoblast-like cells on human laminin 111-coated dishes. Stem Cell Reports. 2013;1(4):322-35.

19. Wang P, Cong M, Liu TH, Yang AT, Cong R, Wu P, Tang SZ, Xu Y, Wang H, Wang BE, Jia JD, You H. Primary isolated hepatic oval cells maintain progenitor cell phenotypes after two-year prolonged cultivation. J Hepatol. 2010;53(5):863-71.

20. Huch M, Gehart H, van Boxtel R, Hamer K, Blokzijl F, Verstegen MM, Ellis E, van Wenum M, Fuchs SA, de Ligt J, van de Wetering M, Sasaki N, Boers SJ, Kemperman $\mathrm{H}$, de Jonge J, ljzermans JN, Nieuwenhuis EE, Hoekstra R, Strom S, Vries RR, van der Laan LJ, Cuppen E, Clevers H. Long-term culture of genome-stable bipotent stem cells from adult human liver. Cell. 2015; 160(1-2):299-312

21. Yanagida A, Ito K, Chikada H, Nakauchi H, Kamiya A. An in vitro expansion system for generation of human iPS cell-derived hepatic progenitor-like cells exhibiting a bipotent differentiation potential. PLoS One. 2013;8(7): e67541.

22. Zhao D, Chen S, Duo S, Xiang C, Jia J, Guo M, Lai W, Lu S, Deng H. Promotion of the efficient metabolic maturation of human pluripotent stem cell-derived hepatocytes by correcting specification defects. Cell Res. 2013. 23(1):157-61.

23. Bastida MF, Sheth $R$, Ros MA. A BMP-Shh negative-feedback loop restricts Shh expression during limb development. Development. 2009;136(22):3779_ 89

24. Li J, Feng J, Liu Y, Ho T-V, Grimes W, Ho HA, Park S, Wang S, Chai Y. BMP$\mathrm{SHH}$ signaling network controls epithelial stem cell fate via regulation of its niche in the developing tooth. Dev Cell. 2015;33(2):125-35.

25. Touboul T, Chen S, C.C. To, Mora-Castilla S, Sabatini K, Tukey RH, Laurent LC. Stage-specific regulation of the WNT/beta-catenin pathway enhances differentiation of hESCs into hepatocytes. J Hepatol. 2016;64(6):1315-26.

26. Hirose $Y$, Itoh T, Miyajima A. Hedgehog signal activation coordinates proliferation and differentiation of fetal liver progenitor cells. Exp Cell Res. 2009:315(15):2648-57.

27. Katsuda T, Kawamata M, Hagiwara K, Takahashi RU, Yamamoto Y, Camargo FD, Ochiya T. YAC-conversion of terminally committed hepatocytes to culturable bipotent progenitor cells with regenerative capacity. Cell Stem Cell. 2017;20(1):41-55.

28. Spence JR, Mayhew CN, Rankin SA, Kuhar MF, Vallance JE, Tolle K, Hoskins EE, Kalinichenko W, Wells SI, Zorn AM, Shroyer NF, Wells JM. Directed differentiation of human pluripotent stem cells into intestinal tissue in vitro. Nature. 2011;470(7332):105-9.

29. Finkbeiner SR, Freeman JJ, Wieck MM, El-Nachef W, Altheim CH, Tsai YH, Huang S, Dyal R, White ES, Grikscheit TC, Teitelbaum DH, Spence JR. Generation of tissue-engineered small intestine using embryonic stem cellderived human intestinal organoids. Biol Open. 2015;4(11):1462-72.

30. Sampaziotis F, de Brito MC, Madrigal P, Bertero A, Saeb-Parsy K, Soares FAC Schrumpf E, Melum E, Karlsen TH, Bradley JA, Gelson WT, Davies S, Baker A, Kaser A, Alexander GJ, Hannan NRF, Vallier L. Cholangiocytes derived from human induced pluripotent stem cells for disease modeling and drug validation. Nat Biotechnol. 2015:33(8):845-52.

31. Takayama K, Kawabata K, Nagamoto Y, Inamura M, Ohashi K, Okuno H, Yamaguchi T, Tashiro K, Sakurai F, Hayakawa T, Okano T, Furue MK, Mizuguchi $H$. CCAAT/enhancer binding protein-mediated regulation of TGF receptor 2 expression determines the hepatoblast fate decision. Development. 2013:141(1):91-100.

32. Ogawa M, Ogawa S, Bear CE, Ahmadi S, Chin S, Li B, Grompe M, Keller G, Kamath BM, Ghanekar A. Directed differentiation of cholangiocytes from human pluripotent stem cells. Nat Biotechnol. 2015;33(8):853-61.

33. Sicklick JK, Li YX, Melhem A, Schmelzer E, Zdanowicz M, Huang J, Caballero M, Fair JH, Ludlow JW, McClelland RE, Reid LM, Diehl AM. Hedgehog signaling maintains resident hepatic progenitors throughout life. Am J Physiol Gastrointest Liver Physiol. 2006;290(5):G859-70.

34. Wang Z, Li W, Li C, Yang Y, Zhang L, Sun S, Li J, Cai Y. Small hepatocyte-like progenitor cells may be a Hedgehog signaling pathway-controlled subgroup of liver stem cells. Exp Ther Med. 2016;12(4):2423-30.

35. Tanaka M, Itoh T, Tanimizu N, Miyajima A. Liver stem/progenitor cells: their characteristics and regulatory mechanisms. J Biochem. 2011;149(3):231-9.

36. Liu H, Kim Y, Sharkis S, Marchionni L, Jang YY. In vivo liver regeneration potential of human induced pluripotent stem cells from diverse origins. Sci Transl Med. 2011;3(82):82ra39. 
37. Yovchev MI, Xue Y, Shafritz DA, Locker J, Oertel M. Repopulation of the fibrotic/cirrhotic rat liver by transplanted hepatic stem/progenitor cells and mature hepatocytes. Hepatology. 2014;59(1):284-95.

38. Lu WY, Bird TG, Boulter L, Tsuchiya A, Cole AM, Hay T, Guest RV, Wojtacha D, Man TY, Mackinnon A, Ridgway RA, Kendall T, Williams MJ, Jamieson T, Raven A, Hay DC, Iredale JP, Clarke AR, Sansom OJ, Forbes SJ. Hepatic progenitor cells of biliary origin with liver repopulation capacity. Nat Cell Biol. 2015;17(8):971-83.

\section{Publisher's Note}

Springer Nature remains neutral with regard to jurisdictional claims in published maps and institutional affiliations.

Ready to submit your research? Choose BMC and benefit from:

- fast, convenient online submission

- thorough peer review by experienced researchers in your field

- rapid publication on acceptance

- support for research data, including large and complex data types

- gold Open Access which fosters wider collaboration and increased citations

- maximum visibility for your research: over $100 \mathrm{M}$ website views per year

At $\mathrm{BMC}$, research is always in progress.

Learn more biomedcentral.com/submissions 